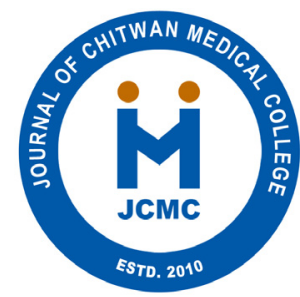

ORIGINAL RESEARCH ARTICLE

\title{
ACUTE PESTICIDE POISONING: REVIEW OF PATIENTS ATTENDING AT EMERGENCY DEPARTMENT IN CHITWAN MEDICAL COLLEGE
}

\author{
DR Lamsal * \\ Department of General Practice and Emergency Medicine Chitwan Medical College, Bharatpur-10, Chitwan, Nepal. \\ *Correspondence to : Dr Daya Ram Lamsal, Chitwan Medical College, Bharatpur-10, Chitwan, Nepal.Email: dayaramlamsal@yahoo.com
}

\begin{abstract}
To find out the hospital based incidence, pattern and fatality of acute pesticide poisoning which may be helpful to develop better management strategy and preventive campaign. A total of 88 patients were reported in emergency with acute pesticide poisoning out of 178 total acute poisoning cases resulting in APP rate $49.43 \%$ of total poisoning cases. Male: Female ratio was 1:1.5. The age group specific incidence of acute poisoning showed $7.95 \%$ in $0-14$ years, $45.55 \%$ in $15-29$ years $30.68 \%$ in $30-44$ years and $12.50 \%$ in $45-59$ years and $3.40 \%$ in 60 years and above. Out of 88 patients $79.55 \%$ admitted, $20.45 \%$ of patient status was unknown as these patients were referred or refused admission. lost follow up .Among admitted patients $8.57 \%$ died and $91.43 \%$ dischared from hospital. Maximum case fatality ratio $(28.57 \%)$ was due to endosulfan poisoning. Pesticide is responsible in $49.43 \%$ of all poisoning patients visiting to emergency department with the mortality of $6.80 \%$ among pesticide poisoning, Women have high morbidity but man predominantly exceeds on mortality rate.. Highest case fatality observed among the endosufan exposed group. How patients are getting such toxic poisons and why these victims are being exposed needs further study. Emphasis on case management and preventive campaigns would have some impact in reducing morbidity and mortality from acute pesticide poisoning.
\end{abstract}

Key Words: Acute pesticide poisoning, morbidity \& case fatality

\section{INTRODUCTION}

Acute pesticide poisoning is any illness or health effect resulting from suspected or confirmed exposure of pesticides within 48 hours. ${ }^{1}$ In developing countries pesticides are the most popular means of self poisoning killing about three hundred thousand population each year. ${ }^{2}$ Introduction of pesticide regulation act and rules operated in 1994 in Nepal could have some positive impact but various study after that also reporting that pesticide poisoning is still hospital is feared to be a continuous tragedy. In this study was carried out to find out the local pattern of poisoning and its fatality based on the patient reported to emergency department in chitwan medical college in Nepal to develop management strategy and preventive campaigns.

\section{MATERIALS AND METHODS}

This retrospective hospital based study was carried out from 1 January 2010 to 31 December 2010 with prior ethical approval from hospital .All patients with poisoning were identified fist and then patients with pesticide poisoning included in the study .Patient were diagnosed on the basis of history, container carried with patient, clinical toxidrome. The data were tabulated and analyzed.

\section{RESULTS}

A total of 88 patients were reported in emergency with acute pesticide poisoning out of 178 all acute poisoning cases resulting in APP rate $49.43 \%$ of total poisoning cases.

Table 1: Gender wise distribution of poisoning cases $(n=88)$

\begin{tabular}{|l|c|c|c|c|}
\hline Poison & Male & Female & Total & Percentage \\
\hline Pesticides & 35 & 53 & 88 & 49.43 \\
\hline Other Poisoning & 47 & 43 & 90 & - \\
\hline Total & 82 & 96 & 178 & - \\
\hline
\end{tabular}

Male: Female ratio was $0.66: 1.0$. The age group specific incidence of acute poisoning showed $7.95 \%$ in $0-14$ years, $45.55 \%$ in $15-29$ years $30.68 \%$ in $30-44$ years and $12.50 \%$ in $45-59$ years and $3.40 \%$ in 60 years and above. 
Table 2: Age group wise distribution and percentile of pesticides poisoning cases $(\mathbf{n}=\mathbf{8 8})$

\begin{tabular}{|l|c|c|c|c|c|c|}
\hline Gender/Age Group & $0-14$ & $15-29$ & $30-44$ & $45-60$ & $\geq 60$ & Total \\
\hline Male & 1 & 17 & 7 & 7 & 3 & 35 \\
\hline Female & 6 & 23 & 20 & 4 & - & 53 \\
\hline Total & 7 & 40 & 27 & 11 & 3 & 88 \\
\hline Percentage (\%) & 7.95 & 45.45 & 30.68 & 12.50 & 3.41 & - \\
\hline
\end{tabular}

Table 3: Disposal of patients with APP $(n=88)$

\begin{tabular}{|l|c|c|}
\hline Disposal & Number (No.) & Percentage (\%) \\
\hline Admission & 70 & 79.55 \\
\hline Recover & 64 & 91.43 \\
\hline Mortality & 6 & 8.57 \\
\hline Unknown* & 18 & 20.45 \\
\hline Total & 88 & - \\
\hline
\end{tabular}

* referred $(n=13)$ and refused admission $(n=5)$

Table 4: Morbidity Patterns according to different types of pesticides poisoning $(n=88)$

\begin{tabular}{|l|c|c|c|c|c|c|}
\hline \multirow{2}{*}{ Pesticide Type } & \multirow{2}{*}{ Male } & \multirow{2}{*}{ Female } & \multirow{2}{*}{$\begin{array}{c}\text { Total } \\
\text { Percentage }\end{array}$} & \multicolumn{2}{|c|}{ Mortality } & \multirow{2}{*}{ Case Fatality Ratio } \\
\cline { 5 - 6 } & & & & Male & Female & \\
\hline Organophosphorus & 19 & 23 & $42(47.73 \%)$ & 2 & 1 & $7.14 \%$ \\
\hline Endosulfan & 3 & 4 & $7(7.95 \%)$ & 2 & - & $28.57 \%$ \\
\hline Cypermethrine & 5 & 11 & $16(18.18 \%)$ & - & - & - \\
\hline Phosphides & 6 & 11 & $17(19.32 \%)$ & 1 & - & $5.88 \%$ \\
\hline Other pesticides & 2 & 4 & $6(6.82 \%)$ & - & - & - \\
\hline Total & 35 & 53 & $88(100 \%)$ & 5 & 1 & $6.82 \%$ \\
\hline
\end{tabular}

\section{DISCUSSION}

Altogether 88 patients admitted with acute pesticide poisoning among them organophosphorus is the commonest compound responsible for acute pesticide poisoning in this study $(47.73 \%$ of total poisoning), which is higher $(43.0 \%)$ than the study conducted in different central and zonal hospital in various parts of country. ${ }^{3}$ The incidence peaks in age group of 15-29 and falls steadily with increasing age in this study which is similar to a study conducted by Gunnel, D. \& Eddleston, M. ${ }^{4}$ Female patients outnumbered male by $1.51: 1$ which is also similar as a study conducted in Bir Hospital, Kathmandu. ${ }^{5}$ Out of 88 patients 5 refused admission and 13 referred to another hospital after initial management due to full occupancy of beds in ICU and ventilatoThe hospital management of pesticide poisoning often requires intensive care, in particular ventilation. In 1995-1996, in one general hospital in Sri Lanka, 41\% of bed occupancy on medical intensive care beds was for the treatment of pesticide poisoning. ${ }^{6}$

The status of these patients are not known due to lack of proper follow up. Case fatality rate is much higher in male than female. The fatality also depend predominantly on the availability and use of highly toxic poison. Endosulfan is found the most lethal agent with $28.57 \%$ fatality in this study. None of the patients died who were exposed to cypermethrine pesticide. Endosulfan was banned in 1998 in Srilanka as there were 50 patient repoterd death due to its poisoning and the following three years the number of endosulfan deaths fell to three. ${ }^{7}$ 


\section{CONCLUSION}

Pesticide is responsible in $49.43 \%$ of all poisoning patients visiting to emergency department with the mortality of $6.80 \%$ among pesticide poisoning, Women have high morbidity but man predominantly exceeds on mortality rate.. Highest case fatality observed among the endosufan exposed group .How patients are getting such toxic poisons and why these victims are being exposed needs further study. Emphasis on case management and preventive campaigns would have some impact in reducing morbidity and mortality from acute pesticide poisoning.

\section{REFERENCES}

1. World Health Organization. Report of a regional workshop 2001. Pesticides poisoning database in SEAR countries. New Delhi 22-24 January 2001.

2. Hawton K, Van Heeringen KE. International Handbook of suicide and attempted suicide 2002. Chichester: John Wiley and Sons.

3. Pokhrel D, Panta S, Pradhan A, Manssor S. A comparative Retrospective Study of Poisoning Cases in Central, Zonal and District Hospitals. Kathmandhu University Journal of Science, Engineering and Technology. Sept 2008;1(5):4448.

4. Gunnel D, Eddleston M. Suicide by intentional ingestion of pesticides: a continuing tragedy in developing countries. International Journal of Epidemiology 2003;32:902-909.

5. Rehiman S, Lohani SP, Bhattarai MD. Correlation of Serum Cholinestarase Level, Clinical Scores at presentation and severity of Organophosphorus poisoning. J Nepal Med Assoc 2008;47(170):47-52.

6. Gunnell D, Eddleston M. Suicide by intentional ingestion of pesticide: a continuing tragedy in developing countries International Journal of Epidemiology 2003;32:902-909.

7. Roberts DM, Karunarathna A, Buckley NA, Manuweera G, Sheriff MH, Eddleston M. Influence of pesticide regulation on acute poisoning deaths in Sri Lanka. Bull World Health Organ 2003;81(11):789-98. 